\title{
O USO DAS METODOLOGIAS ATIVAS NA EDUCAÇÃO
}

Ana Elisa Pillon ${ }^{1}$ Araci Hack Catapan ${ }^{2}$ Márcio Vieira de Souza ${ }^{3}$

\section{RESUMO}

A educação acompanha a evolução da sociedade, que, na atualidade, é denominada "do conhecimento", enfatizando a simbiose entre tais temas. Seu histórico, iniciado por um processo de endoculturação, vislumbra a Educação a Distância como modalidade de ensino com maior índice de crescimento e, atualmente, busca aprimorar suas ações ao utilizar as mais variadas técnicas pedagógicas. A partir desta discussão, o objetivo deste estudo é abordar a temática metodologias ativas observando sua inserção na educação como auxiliar no processo de construção de autonomia dos estudantes na sua busca pelo conhecimento. Para atender a este objetivo, trabalhou-se a partir de uma busca exploratória-descritiva da literatura, na qual o resultado foi analisado por meio da abordagem qualitativa. Estes procedimentos metodológicos permitiram identificar que o tema metodologias ativas vêm sendo debatido, porém pode-se inferir que há a necessidade de novos trabalhos teórico-práticos que reforcem a importância do assunto para que a educação possa acompanhar a evolução da sociedade atual.

Palavras-Chave: Blended Learning. Educação a Distância. Metodologias ativas.

Peer Instruction. Problem Based Learning. 


\section{INTRODUÇÃO}

A sociedade atual não pode ser comparada à de alguns anos atrás sem que inúmeros fatores sejam declarados como "diferenciados". A sociedade mudou, o modo como o trabalho é exercido foi se modificando, a maneira como a educação é permeada foi aprimorada e, acompanhando esta evolução, a exigência quanto às características pessoais e profissionais também se encontra diferenciada dos tempos de outrora.

Em destaque na reportagem A Revolução da Educação (LIMA, 2018), aspectos que nos chamam a atenção são: o sistema educacional precisa aprimorar suas principais características e o perfil do estudante que buscamos formar precisa estar condizente com a sociedade de convergência em que nos encontramos inseridos. A educação, utilizando-se das mais variadas técnicas, deve ter como principal objetivo deixar para trás a educação bancária apontada por Paulo Freire, autor-chave da área. Para este autor, o que ele denominou de "educação bancária" retrata um sistema reprodutor do saber, que faz uso da vigilância, da punição e do exame.Brighente e Mesquida (2016) salientam que, neste tipo de educação opressora, não há a busca pela conscientização dos estudantes, pois o professor apenas “deposita” os conteúdos nas suas cabeças, como se estas representassem recipientes a serem preenchidos. $\mathrm{O}$ segundo tópico que necessita de uma análise - perfil do estudante - também foi foco de estudo de Paulo Freire. Em sua obra denominada Pedagogia da Autonomia, o autor ressalta que a educação deve ter por tarefa propiciar condições através das quais as pessoas tenham a possibilidade de se assumirem como seres sociais e históricos, pensantes, comunicantes e transformadores (FREIRE, 2000).
A ênfase apontada por Paulo Freire vem de encontro ao apresentado por Cardoso et al. (2017).Para a autora,o modelo econômico atual tem exigido cada vez mais dos profissionais a capacidade de organizar informações e utilizar o conhecimento adquirido em seu dia a dia. Para alcançar este patamar a autora salienta que o uso de metodologias ativas pode auxiliar os estudantes, dando-lhes a possibilidade de exercer um papel mais ativo e, desta forma, oferecendo-lhes uma maior autonomia no seu próprio processo de ensinar e aprender. Tendo em vista o escopo abordado inicialmente - a relevância da educação para o cenário atual -, neste estudo, serão apresentados dados relevantes sobre a evolução do processo educacional, o crescimento da Educação a Distância, o ensino híbrido como prática inovadora nesta modalidade de ensino e, por fim, duas opções de metodologias ativas que têm sido comumente utilizadas com a finalidade de formar estudantes aptos ao mercado cada vez mais competitivo.

A fim de alcançar os objetivos propostos, no que tange à sua natureza, esta pesquisa refere-se à metodologia aplicada tem por propósito apresentar novos conhecimentos, capazes de serem utilizados na prática. Quanto à abordagem, foi utilizada a análise qualitativa. De acordo com Gil (2008), este tipo de análise considera que existe uma relação dinâmica entre o mundo real, objetivo, e o sujeito, que não pode ser traduzido em números. Além disso, neste estudo, a metodologia utilizada, quanto a seus objetivos, denomina-se exploratória, tendo em vista a intenção de esclarecer uma questão abordada. Para este fim, o referencial teórico foi baseado em uma pesquisa bibliográfica efetivada através da análise de artigos e livros que abrangem os temas-base. 


\section{A EVOLUÇÃO DA EDUCAÇÃO}

A educação vem se modificando progressivamente, acompanhando a evolução de uma sociedade que, na atualidade, é definida como "do conhecimento". Segundo Costa e Rauber (2009), na época das sociedades primitivas, o processo educativo ocorria somente por métodos informais, através da endoculturação. Neste modelo, os valores, princípios e costumes eram transmitidos de geração a geração por intermédio da convivência em sociedade e este era o único mecanismo utilizado para este fim. Porém, somente a partir de 13.000 a.C., quando, através de gravuras em pedras em cavernas, foram registrados os primeiros ensaios de escrita, que iniciaram o processo educativo considerado formal.

Segundo Alves (2011), NA

ETAPA SEGUINTE, TAIS REGISTROS

PASSARAM A SURGIR EM DIFE-

RENTES PONTOS DO MUNDO POR

INTERMÉDIO DO MODELO CO-

NHECIDO ATÉ OS DIAS DE HOJE

COMO "ENSINO PRESENCIAL" OU,

AINDA, "ENSINO CONVENCIONAL".

ESTE TIPO DE MÉTODO EDUCA-

CIONAL TEM SIDO UTILIZADO

PARA CURSOS REGULARES EM

QUE PROFESSORES E ESTUDANTES

SE ENCONTRAM EM SALAS DE AULAS FÍSICAS, OS ENCONTROS TÊM DATA FIXA E, AINDA, A TRANSMISSÃO DO CONHECIMENTO É PASSADA AOS ESTUDANTES EM TEMPO REAL.
De acordo com Brito (2015), até a Idade Média, o conhecimento não alcançava a todos e, nesta fase, a educação inicia sua perspectiva por formar pessoas para o trabalho.A partir deste momento, então, conforme o autor, a necessidade de aprimorar a produção e aumentar as vendas através de agilidade incentivou o desenvolvimento de novas tecnologias de comunicação, que, por conseguinte, influenciaram a área educacional. Dentre as mudanças que ocorreram na sequência, no século XVI, a imprensa impulsiona o desenvolvimento começando a transmitir informações via correspondência e, no século XVIII, temos os primeiros registros em jornais de cursos de taquigrafia oferecidos a Distância. Foi, no entanto, somente no século XIX que a Educação a Distância surge efetivamente como uma modalidade de ensino. Para este autor, a Educação a Distância é um método de ensino em que os professores e os estudantes se encontram fisicamente distantes, porém se comunicam a distância, tendo por auxiliares tecnologias de longo alcance.

O ensino na modalidade a Distância se encontra em crescimento em todo o mundo. Tal fato deve-se a dois importantes fatores: o incentivo decorrente da diversidade de opções de estudo através das Tecnologias da Informação e Comunicação e a capacidade de inserção em todos os tipos de processos produtivos. Por intermédio destas peculiaridades, a Educação a Distância (EaD) é vista por pessoas e instituições como a principal forma de democratizar o acesso ao conhecimento e expandir as oportunidades para adquirir novos conhecimentos importantes para o sucesso pessoal e profissional (BRITO, 2015). 
O aumento descrito pelo autor confirma-se no último Censo EaD.BR, que aponta Educaçãoa

Distância como a modalidade educacional que apresenta o maior crescimento na história da educação (CENSO, 2017).

\section{A EDUCAÇÃO A DISTÂNCIA}

A Educação a Distânciaé definida por inúmeros autores. Para Moore e Kearsley (2008), a principal característica da Educação a Distância refere-se à situação de distanciamento entre os estudantes e os professores, pois estes se encontram em locais diferentes.

Em consonância à questão, Oroja, Kotoua e Ilkan (2011) a definem como um processo de aprendizagem no qual a tecnologia é utilizada para diferentes partes deste processo: matrícula, design, distribuição de conteúdo, avaliação e, ainda, apoio aos estudantes. Além disso, reforçam que os autores, professores e estudantes têm a possibilidade de participar do processo ensino-aprendizagem mesmo estando em qualquer lugar do mundo e a qualquer momento.

Para Gnecco Júnior (2012), um dos importantes diferenciais da Educação a Distância refere-se ao fato de ela permitir novas oportunidades de aprendizado e compartilhamento de conhecimento a um grande número de pessoas que não possuíam esta possibilidade, configurando o que comumente é citado como um dos principais objetivos deste modelo de ensino: a democratização da educação.

Oficialmente, a Educação a Distância foi reconhecida por intermédio da Lei de Diretrizes e Bases da Educação Nacional (LDB), Lei Federal no 9.394, de 1996 e regulamentada pelo Decreto 5.622, de 2005. De acordo com esta lei, a EaD representa a modalidade de ensino na qual a mediação didático-pedagógica nos processos de ensino e aprendizagem ocorre através da utilização de meios e tecnologias de informação e comunicação, em que estudantes e professores desenvolvem as atividades educativas em lugares ou tempos diversos (BRASIL, 2007).

Segundo Bielschowsky (2018), os dados referentes à $\mathrm{EaD}$ são impressionantes. $\mathrm{O}$ número de matrículas que em 2004 era de 59,6 mil passou a ser, em 2016, cerca de 1,5 milhão de matrículas. Outro aspecto salientado pelo autor comprova que esta modalidade supera as demais, tendo em vista que, dentre as 4 milhões de matrículas adicionais ocorridas no ensino superior no período entre 2004 e 2016, o total de 1,45 milhão das novas matrículas ocorreu na modalidade a Distância. O aumento do número de alunos também é considerado muito alto, pois, de acordo com o Censo EAD.BR 2016, em 2014, havia 519.839 alunos; em 2015, 498.683 alunos; e, em 2016 o índice passou a 561.667 alunos matriculados nesta modalidade de ensino (CENSO, 2017).

Confirmando tal posicionamento e os dados do último Censo publicado que comprovam que a EaD é a modalidade educacional que apresenta o maior crescimento na história da educação, cresce também a necessidade de desenvolver 
abordagens diferenciadas que possam suprir as necessidades dos estudantes das gerações digitais, propiciando-lhes uma formação mobilizadora.Neste sentido, no próprio Censo EaD. $\mathrm{Br}$, foram apontadas as maiores dificuldades enfrentadas pelas instituições que atuam com a $\mathrm{EaD}$, dentre as quais apresenta-se a necessidade de inovar suas abordagens pedagógicas e, também, a carência de oferecer inovação tecnológica constante. Em busca da solução para tais problemas apontados, o Censo apresenta como uma das possibilidades para as instituições aprimorarem sua capacidade de sobreviver e ter um diferencial neste mercado em expansão a utilização de metodologias ativas, tais como, aprendizagem baseada em problemas-Problem Based Learning ou PBL, aprendizagem baseada em projetos, gamificação, sala de aula invertida, design thinking, peer instruction - que em português é definido como instrução entre pares, entre outras (CENSO,2017). As metodologias ativas podem ser utilizadas no decorrer das aulas presenciais, intercaladas com as aulas on-line, partes de um ensino denominado híbrido (ou blended learning).

\section{O MODELO HÍBRIDO (BLENDED LEARNING)}

A literatura atual ressalta que a educação contemporânea já não comporta um modelo tradicional de ensino, utilizado satisfatoriamente no passado. Moran (2015) salienta, por exemplo, que, para vencer as inovações - tecnológicas, ambientais, sociais -, o ensino formal está sendo mesclado com o modelo híbrido, na tentativa de suprir as necessidades do público estudantil cada vez mais ativo. Para este autor, o ensino híbrido é uma tendência promissora, capaz de atender à demanda das transformações sociais presentes.

No ensino híbrido, a educação ocorre de uma forma diferenciada, em que há a constante promoção de atividades com foco no desenvolvimento das competências individuais primordiais para tornar possível o sucesso na sociedade atual. Neste modelo, tanto o professor como os estudantes assumem novas atribuições: o estudante precisa assumir o papel de protagonista do seu aprendizado, e o professor atua como um facilitador deste processo (MORAN,2015).

Segundo Moran (2015), o ensino híbrido integra as atividades de sala de aula com os espaços virtuais. Neste formato, o aluno resolve as questões práticas do seu aprendizado em espaços físicos e, ainda, ao utilizar as tecnologias digitais, participa da troca de ideias entre seus colegas, enriquecendo seus conhecimentos, além de romper, desta forma, as barreiras geográficas de tempo e espaço.

Complementando tal posicionamento, de acordo com Valente (2014), o ensino híbrido tem importante papel na educação. Por intermédio de sua prática, utilizando metodologias ativas, o ensino híbrido prepara os estudantes para a atualidade, pois, além de reter a informação que recebeu, o aluno precisa ressignificar estes novos conhecimentos e conseguir aplicá-los em situações concretas. 


\section{AS METODOLOGIAS ATIVAS}

Berbel (2011) define as metodologias ativas como sendo as práticas de ensino e aprendizagem que utilizam experiências reais ou simuladas com o objetivo de solucionar uma situação específica. Mitre et al. (2008) complementam salientando que, ao utilizar a "problematização", os alunos são motivados a encontrar a resolução de um problema a partir da reflexão e da relação à sua história pessoale/ou profissional, de modo que assim seja potencializada a construção do seu conhecimento.

Nessa perspectiva, Cunha et al. (2017) destacam que diante de um cenário competitivo em busca de melhor colocação profissional, criar estratégias ativas para ensinar e aprender tornou-se uma necessidade, bem como um diferencial imprescindível, tanto para o docente quanto para o estudante. De acordo com os autores, este processo educativo “[...] encoraja o aprendizado crítico-reflexivo, onde o participante tem uma maior aproximação com a realidade [...]", possibilitando assim a ampliação de estímulos na busca de soluções (CUNHA et al., 2017, p. 52). Dessa forma, diante do exposto, pode-se inferir que trabalhar com metodologias ativas exige do professor e do estudante uma participação em atividades intensivas em conhecimento.

Em consonância ao apresentado, Borges e Alencar (2014) salientam que, na atual concepção educacional, em que a troca de experiências e culturas tornou-se uma constante, o docente tem papel primordial, especialmente ao considerar que o aprendizado crítico e reflexivo dos estudantes poderá resultar da sua prática e disponibilização dos mais variados recursos didáticos. É importante dispor, neste ponto, da premissa apontada por Hinckel (2015), no qual, de acordo com a autora, na Conferência deJomtien,em 1990, destacou-se a importância em oferecer uma educação capaz de transpor os estudantes para além da mera exposição de conteúdos abstratos e conceituais, tornando-os aptos a perceber os mais diversos talentos e afinidades capazes de aprimorar seu crescimento pessoal, social e, ainda, profissional. Para este objetivo, a autora destaca ainda a necessidade da criação de "elos" entre as esferas educação-postura e docente-prática pedagógica, baseados nos quatros pilares da educação e do conhecimento: aprender a conhecer - exercitar a atenção, memória e pensamento; aprender a fazer - relacionar teoria e prática; aprender a viver juntos - gerir conflitos e valorizar as redes de relacionamento; e aprender a ser - desenvolver capacidades como autonomia, discernimento, raciocínio e comunicação.

Com base nestas considerações, cabe ressaltar a importância de identificar o perfil do estudante, visto que, de acordo com Hinckel (2015,p.133), “[...] os métodos de ensino tradicional já não atendem às necessidades e preferências desta nova geração de estudantes”. A partir desta afirmativa, a fim de propiciar o aprimoramento das habilidades dos estudantes da atualidade, torna-se fundamental que os professores possibilitem a seus alunos diversificadas e novas 
experiências, além de atuar de forma que seja oportunizada uma mediação pedagógica capaz de oferecer o progressivo diálogo (SOARES JUNIOR; PORTO, 2017).

Segundo Mitre et al. (2008), as metodologias ativas podem aprimorar, de maneira significativa e eficaz, o processo ensino-aprendizagem. Para a autora, sugere-se a utilização de problematizações como auxiliares no escopo das metodologias ativas, motivando os estudantes, pois, quando colocados perante um problema, estes promovem autoexame, reflexão e análise contextual, resultando na ressignificação das possíveis descobertas encontrados pelos alunos.

Concomitante ao apresentado, Berbel (2011) afirma que as metodologias ativas, ao passo que utilizam as experiências reais ou simuladas com o intuito de solucionar, com sucesso, os desafios das atividades essenciais pertinentes à prática social, têm como resultado o desenvolvimento do processo de "aprender".

Dentre as metodologias ativas citadas pelo Censo EAD.BR, temos o peer instruction e o Problem Based Learning - PBL, apresentados a seguir.

\subsection{Peer instruction}

O Peer instruction, ou aprendizado pelos pares, foi proposto em 1997 pelo professor Eric Mazur, na Universidade de Harvard. O principal objetivo do professor foi criar uma metodologia para promover a aprendizagem a partir do envolvimento dos estudantes na solução de problemas relacionados aos conteúdos. Desta forma, ao invés de permanecerem passivos recebendo os conteúdos transmitidos pelo professor, inverte-se a sala de aula e os estudantes preparam-se em casa para a solução das questões que serão trabalhadas naquele momento (SILVA; OLIVEIRA, 2017).

No método ativo, denominado peer instruction, os estudantes realizam um estudo prévio do material disponibilizado pelo professor e, após, participam da discussão em sala de aula com os colegas, apresentando as questões conceituais (ARAÚJO; MAZUR, 2013).

O objetivo desta metodologia é aprimorar as aulas, tornando-as mais interativas e fazendo com que os alunos interajam entre si, explicando uns aos outros os conceitos estudados. As aulas são divididas em pequenas séries de apresentações orais em que o professor apresenta ao grupo os principais conceitos a serem trabalhados, e, na sequência, os alunos recebem questões conceituais para serem respondidas, num primeiro momento, de forma individual e, então, passam à discussão com seus colegas. Após esta apresentação oral, o professor apresenta aos alunos uma questão conceitual com o intuito de avaliar suas compreensões sobre os principais temas abordados (FONSECA; MATTAR NETO, 2017). Na Figura 1, observa-se um fluxograma com esta sequência. 


\section{Figura 1: Fluxograma para a aplicação do peer-instruction}

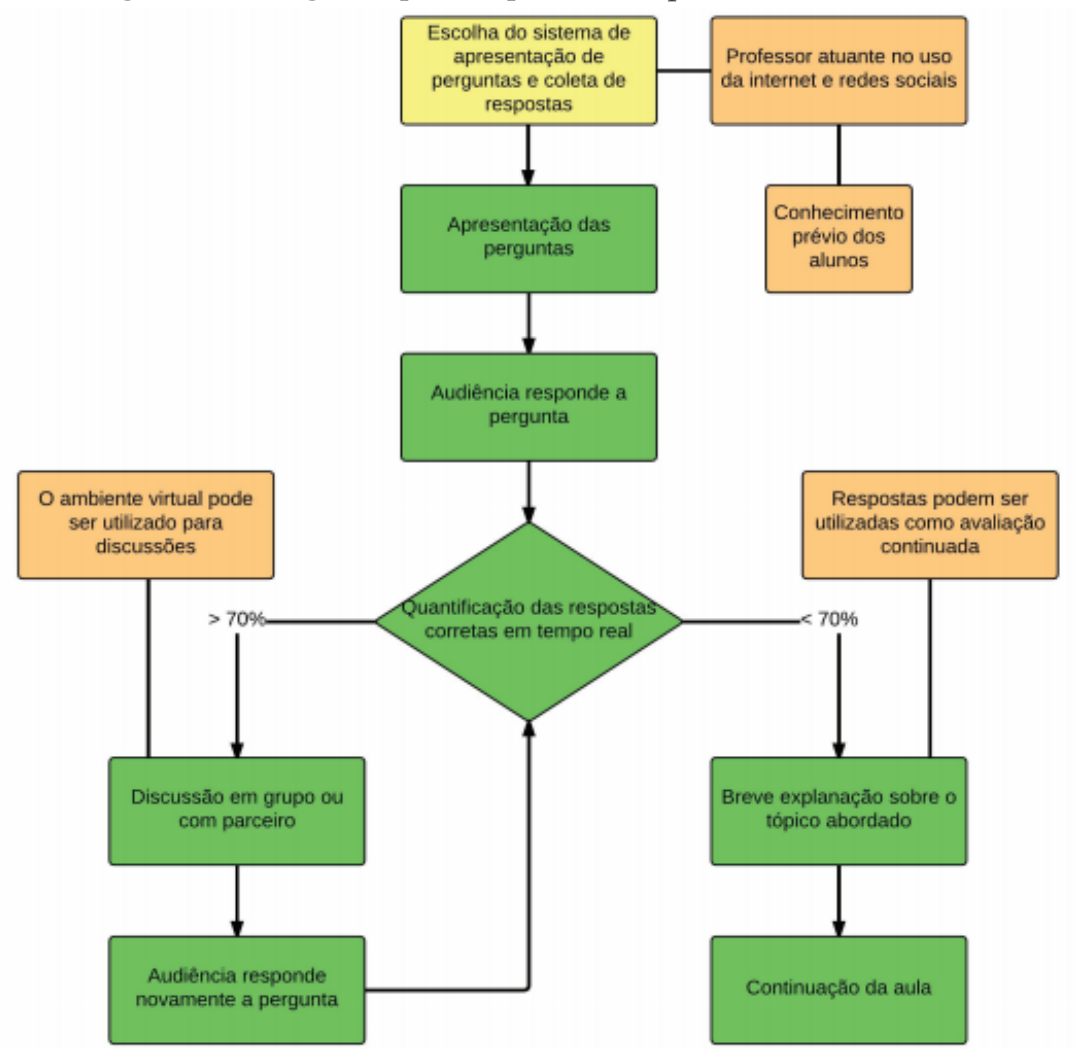

Fonte: Lima e Santos (2016)

No fluxograma para a aplicação do peer-instruction apresentado por Lima e Santos (2016), os itens que estão em verde demonstram as etapas consideradas tradicionais; os ícones em laranja representam as partes que auxiliam e aumentam a eficácia do método; e, em amarelo, é apresentado o ponto chave deste trabalho.

Segundo Lima e Santos (2016), o peer instruction,ou PI,como échamado por alguns autores, é uma das mais importantes metodologias ativas de ensino-aprendizagem, pois estimula os estudantes a obterem feedback em tempo real e com precisão sobre determinado conceito apresentado em sala de aula.

\subsection{Problem Based Learning (PBL)}

Problem-Based Learning (PBL), ou Aprendizagem Baseada em Problemas, é uma abordagem da educação voltada para o desenvolvimento de habilidades (SAVERY, 2006), que pode ser utilizada tanto como estratégia didática como estruturação de currículo de cursos.

Segundo Lopes et al.(2011), metodologia surgiu na década de 60, na faculdade de medicina da Universidade McMaster, no Canadá, com o objetivo de diminuir a defasagem existente entre os anos iniciais do curso - caracterizados por formação apenas teórica, com a fase de prática médica dos estudantes. Pensando em eliminar este gap, o currículo utilizando PBL permitiu uma relação possível entre prática/ teoria/prática, fazendo com que os estudantes estejam no centro do processo de aprendizagem, aplicando diferentes áreas de conhecimento na resolução de problemas que condizem com situações similares aos presentes na realidade. 
No Brasil, a PBLiniciou sua trajetória da mesma forma em currículos do curso de medicina, porém, na atualidade, vem sendo adotada por um número cada vez maior de instituições que buscam formar profissionais capazes de desenvolver hábitos de raciocínio, pesquisa e resolução de problemas(FONSECA;MATTAR NETO, 2017).

Cabe ressaltar, no entanto, que, muitas vezes, a metodologia PBLé confundida com a resolução de problemas, sendo reduzida somente a esta ação. Sardo (2007) reforça que o problema deve ser considerado o princípio desta ação metodológica, em que a estratégia auxilia os estudantes a identificarem suas próprias limitações de aprendizagem e, também, a aplicar as informações utilizando atividades em que a aprendizagem em grupo é um diferencial. $\mathrm{O}$ problema será o ponto de partida, bem como o componente fundamental do processo, pois, por intermédio dele, serão organizados os ciclos de atividades.

De acordo com Lopes et al. (2011), a PBL segue um ciclo de aprendizagem que inicia com a apresentação do cenário do problema aos estudantes. Em seguida, os estudantes devem analisar e reformular o problema, identificando os fatos que consideraram relevantes no cenário apresentado. Na sequência, após refletir sobre as deficiências encontradas - utilizando trabalhos em equipe e estudos dirigidos - cada estudante deverá aplicar os novos conhecimentos resultantes da sua reflexão sobre seu momento individual durante o processo de construção coletiva. $\mathrm{Na}$ Figura 2, pode-se observar tais etapas.

Figura 2: $\mathrm{O}$ ciclo de aprendizagem na PBL

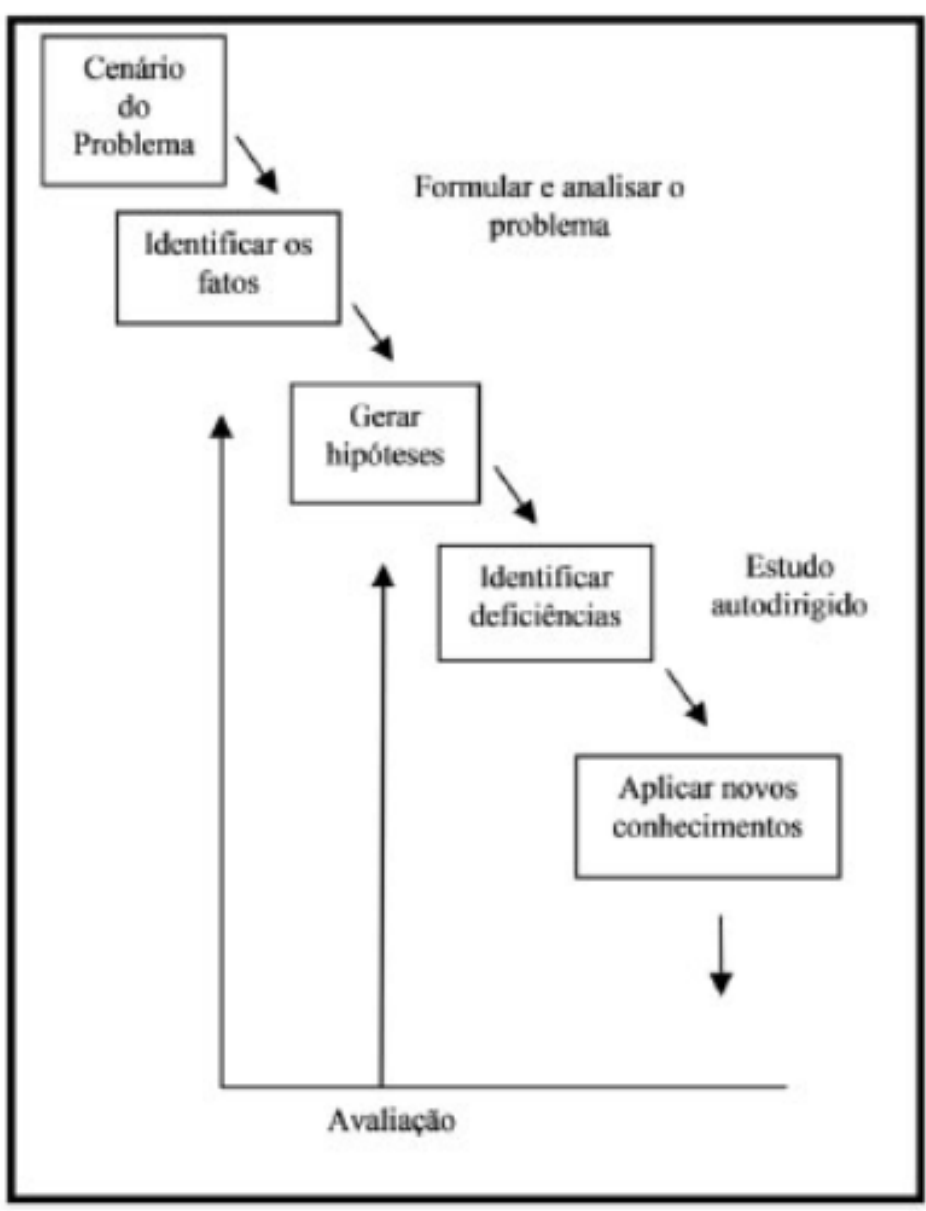

Fonte: Lopes et al. (2011) 
Conforme apontam Lopes et al. (2011), a utilização da metodologia de ensino PBL propicia a interdisciplinaridade, ao passo que favorece a construção de novos conhecimentos de diferentes campos disciplinares, como também é responsável por aprimorar a autonomia e a responsabilidade dos estudantes quanto ao seu próprio aprendizado, resultados primordiais na constituição das novas competências exigidas no mercado atual.
Em consonância, Farias, Spanhol e Souza (2016) ampliam este escopo ao destacarem que o indivíduo em formação que utiliza a Aprendizagem Baseada em Problemas (PBL) amplia sua performance pelo desenvolvimento de diferentes habilidades, como: interação social, trabalho em grupo,liderança, comunicação e colaboração.

\section{CONCLUSÃO}

A área educacional acompanha as evoluções de uma sociedade em constante mutação e, neste sentido, tem o importante papel de oferecer situações de ensino-aprendizagem que possibilitem aos estudantes aprimorar suas competências em busca do melhor desempenho e resultados, em um mercado cada vez mais competitivo. O modelo tradicional, conclui-se, precisa ser atualizado, revisto em suas práticas, motivo pelo qual a Educação a Distância, bem como a utilização do modelo híbrido, apresentam-se como métodos tão relevantes.

Em seu trabalho intitulado "Educação à Distância: sua evolução e sua relevância nos dias atuais”, Brito, Oliveira e Bezerra (2015) reafirmam que a $\mathrm{EaD}$ é entendida como uma modalidade de educação capaz de realizar um processo de construção do conhecimento crítico e criativo. Por sua vez, Tori (2009) salienta que as estratégias que envolvem o ensino híbrido convergem os principais benefícios dos dois momentos: a presença do professor e a interação face a face nas aulas presenciais e a disponibilidade dos materiais e objetos de aprendizagem em tempo integral, na EaD. Para os momentos presenciais, a utilização das metodologias ativas atua como uma possibilidade de formação e desenvolvimento na sociedade contemporânea e, desta forma, estudos na área são importantes, visto a possibilidade de construção significativa do conhecimento por intermédio das diferentes metodologias que poderão ser utilizadas (LEITE; RAMOS, 2017). Na mesma linha de pensamento, Moran (2015) afirma que, nas metodologias ativas de aprendizagem, o aprendizado se dá a partir de problemas e situações reais; os mesmos que os alunos vivenciarão depois na vida profissional, de forma antecipada, durante o curso.

Para Mitre et al. (2008), as metodologias ativas que tem sido empregadas como abordagens pedagógicas - das quais se cita a PBL e o peer instruction - podem ser consideradas responsáveis por desenvolver nos estudantes a habilidade de "aprender a aprender" - que envolvem a construção de capacidades, como "aprender a conhecer”, o "aprender a fazer”, o "aprender a conviver" o "aprender a ser". Desta fora, a partir desta revisão bibliográfica, pode-se finalizar salientando que o processo educacional pode ser aprimorado com a utilização de diferentes metodologias ativas, buscando desenvolver nos estudantes competências apontadas como imprescindíveis para o seu sucesso, tais como: liderança, senso empreendedor,interdisciplinaridade, habilidades digitais, entre outras. 


\section{THE EVOLUTION AND USE OF ACTIVE METHODOLOGIES IN EDUCATION}

\begin{abstract}
Education follows the evolution of society, which today is called "knowledge" emphasizing the symbiosis between such themes. Its history, initiated by an endoculturation process, sees distance education as the teaching modality with the highest growth rate and currently seeks to improve its actions by using the most varied pedagogicaltechniques. From this discussion the aim of this study is to approach the thematic active methodologies observing its insertion ineducation as an aid in the process of buildingstudents'autonomy in their quest for knowledge. To meet this objective, we worked on an exploratory-descriptivesearch of the literature, in which the result was analyzed through the qualitative approach. These methodological procedures allowed us to identify that the topic of active methodologies has been debated, but it can be inferred that there is a need for new theoretical-practical works that reinforce the importance of the subject so that education can follow the evolution of the current society.
\end{abstract}

KEYWORDS: Blended Learning.
Distance education. Active
methodologies. Peer Instruction.
Problem Based Learning.

KEYWORDS: Blended Learning.

Distance education. Active

methodologies. Peer Instruction.

Problem Based Learning.

\section{REFERÊNCIAS}

ALVES, L. Educação a Distância: conceitos e história no Brasil e no mundo. Revista Brasileira de Aprendizagem Aberta e a Distância, São Paulo, art. 7, 2011. Disponível em: http://www.abed. org.br/revistacientifica/Revista_PDF_Doc/2011/ Artigo_07.pdf. Acesso em: 31 out. 2018.

ARAUJO, I. S.; MAZUR, E. Instrução pelos colegas e ensino sob medida: uma proposta para o engajamento dos alunos no processo de ensinoaprendizagem de Física. Caderno Brasileiro de Ensino de Física, [s.1.], v. 30, n. 2, p. 362-384, 17 abr. 2013. Universidade Federal de Santa Catarina (UFSC). http://dx.doi.org/10.5007/21757941.2013v30n2p362. Disponível em: https:// periodicos.ufsc.br/index.php/fisica/article/ view/26150. Acesso em: 11 nov. 2018.

BERBEL, N. A. N. As metodologias ativas e a promoção da autonomia de estudantes: Ciências Agrárias. Semina: Ciências Sociais e Humanas, Londrina, Paraná/PR, v. 32, n. 1, p. 25-39, jan./jun., 2011. Universidade Estadual de Londrina.

BIELSCHOWSKY, C. E. Qualidade na Educação Superior a Distância no Brasil: Onde Estamos, para Onde Vamos? EaD em Foco, [s.1.], v. 8, n. 1, p. 1-26, 28 mar. 2018. Fundação CECIERJ. http:// dx.doi.org/10.18264/eadf.v8i1.709. Disponível em: http://eademfoco.cecierj.edu.br/index.php/Revista/ article/view/709. Acesso em: 11 nov. 2018.

BORGES, T. S.; ALENCAR, G. Metodologias Ativas na promoção da formação crítica do estudante: $\mathrm{O}$ uso das metodologias ativas como recurso didático na formação crítica do estudante do ensino superior. Cairu em Revista. 2014. Disponível em: https://ufsj.edu.br/ portal2-repositorio/File/napecco/Metodologias/ Metodologias\%20Ativas \%20na\%20Promocao\%20 da\%20Formacao.pdf. Acesso em: 14 out 2018.

BRASIL. Ministério da Educação. Secretaria de Educação a Distância. Referenciais de Qualidade para Educação Superior a Distância. Brasília, ago. 2007. [on-line]. Disponível em: http://portal.mec. gov.br/seed/arquivos/pdf/legislacao/refead1.pdf. Acesso em: 10 set. 2018. 
BRIGHENTE, M. F.; MESQUIDA, P. Paulo Freire: da denúncia da educação bancária ao anúncio de uma pedagogia libertadora. Pro-posições, [s.1.], v. 27, n. 1, p.155-177, abr. 2016. FapUNIFESP (SciELO). http://dx.doi.org/10.1590/0103-7307201607909.

BRITO, D. F. B. de; OLIVEIRA, R. D. de; BEZERRA, D. C. da C. M. Educação a Distância: sua evolução e sua relevância nos dias atuais. Anais do Sciencult, Paranaíba, v. 6, n. 1, p.277-291, 2015. ISSN ELETRÔNICO: 2175-8719.

CARDOSO, S. O. dos S.; OLIVEIRA, E. B. de O.; CAMARGO, L. S.; JORGETO, F. A.; CANCIAN, W. C.; ZANONI, E.; TERRA, R. R. P.; SILVA, C. A. da; SHIMOHIGASHI, E. R. M. A utilização de metodologias ativas como instrumento de autonomia e forma de aprendizagem para o aluno do ensino a distância. Apresentações Trabalhos Científicos, [s.1.], p. 1-10, 20 set. 2017. Associação Brasileira de Educação a Distância ABED. http://dx.doi. org/10.17143/ciaed/xxiilciaed.2017.00383.

CENSO EAD.BR 2016: Relatório analítico da aprendizagem a distância no Brasil - Censo EAD. BR 2016: analytic report of distance learning in Brazil [livro eletrônico]/[organização] ABED - Associação Brasileira de Educação a Distância; [Tradução de Maria Thereza Moss de Abreu]. Curitiba: InterSaberes, 2017. Disponível em: http://abed.org. br/censoEaD2016/Censo_EAD_2016_portugues. pdf. Acesso em: 11 nov. 2018.

COSTA, E. de B. O.; RAUBER, P.. História da educação: surgimento e tendências atuais da universidade no Brasil. Revista Jurídica Unigran, Dourados, MS, v. 11, n. 21, p.241-253, Jan/Jun 2009. Disponível em: http://www.unigran.br/revista juridica/ed_anteriores/21/artigos/artigo15.pdf. Acesso em: 10 out 2018 .

CUNHA, G. I. C. da; CUNHA, J. I. C. da; MONTE, W. S. do; JESUS, S. M. S. de. Metodologias Ativas no Processo de Ensino Aprendizagem: Proposta Metodológica para Disciplina Gestão de Pessoas In: SILVA, A. R. L. da; BIEGING, P.; BUSARELLO, R. I. (Org.). Metodologia ativa na educação. São Paulo: Pimenta Cultural, 2017. 150 p. ISBN: 978-85-66832-59-4. Disponível em: https://www. pimentacultural.com/metodologia-ativa-na-educacao. Acesso em: 13 out. 2018.
FARIAS, G. F.; SPANHOL, F. J.; SOUSA, M.V. The use of LMS to support PBL practices: A systematic review. Journal of Research \& Method in Education, v. 6, p. 3, 2016.

FONSECA, S. M.; MATTAR NETO, J. A. Metodologias ativas aplicadas à Educação a Distância: revisão de literatura. Revista EDaPECI, São Cristóvão (se), v. 17, n. 2, p. 185-197, maio 2017. Quadrimestral. ISSN: 2176-171X. Disponível em: https://seer.ufs.br/index.php/edapeci/article/ view/6509. Acesso em: 17 nov. 2018.

FREIRE, P. Pedagogia da autonomia: saberes necessários à prática educativa. 50. ed. Rio de Janeiro: Paz e Terra, 2000.

GIL, A. C. Como elaborar projetos de pesquisa. 4. ed. São Paulo: Atlas, 2008.

GNECCO JUNIOR, L. Desafios na gestão de cursos EaD: um estudo de caso nos cursos de Administração a distância da UFSC. 2012. 292 f. Dissertação (Mestrado) - Universidade Federal de Santa Catarina, Centro Socioeconômico. Programa de Pós-Graduação em Administração.

HINCKEL, N. C. A escola e as competências para o século XXI. In: EHLERS, A. C. da S. T.; TEIXEIRA, C. S.; SOUZA, M. V. de. Educação fora da caixa: tendência para a educação no século XXI. Florianópolis/SC: Bookess, 2015. p. 61-82. ISBN 978-85-448-0239-7.

LEITE, L. S., RAMOS, M. B. A metodologia Ativa no Ambiente Virtual de Aprendizagem. In: SILVA, A. R. L. da; BIEGING, P.; BUSARELLO, R. I. (Org.). Metodologia ativa na educação. São Paulo: Pimenta Cultural, 2017.150 p. ISBN: 978-85-66832-59-4. Disponível em: https:// www.pimentacultural.com/metodologia-ativa-naeducacao. Acesso em: 13 out. 2018.

LIMA, L. Revolução na Educação. Você S/A: Revolução na Educação, São Paulo, SP, n. 241, p.2637, 1 jun. 2018. 
LIMA, B. S. de; SANTOS, C. A. M. dos. Peerinstruction Usando Ferramentas On-line. Revista de Graduação USP, [s.1.], v. 1, n. 1, p. 83-90, 18 jul. 2016. Universidade de São Paulo Sistema Integrado de Bibliotecas - SIBiUSP. http://dx.doi. org/10.11606/issn.2525-376x.v1i1p83-90.

LOPES, R. M.; SILVA FILHO, M. V.; MARSDEN, M.; ALVES, N. G. Aprendizagem baseada em problemas: uma experiência no ensino de química toxicológica. Química Nova, [s.1.], v. 34, n. 7, p. 1275-1280, 2011. FapUNIFESP (SciELO). http:// dx.doi.org/10.1590/s0100-40422011000700029.

MITRE, S. M. I.; SIQUEIRA-BATISTA, R.; GIRARDI-DE MENDONÇA, J. M.; MORAISPINTO, N. M.; MEIRELLES, C.A.B.; PINTOPORTO, C.; MOREIRA, T.; HOFFMANN, L. M. Al. Metodologias ativas de ensino-aprendizagem na formação profissional em saúde: debates atuais. Ciência e Saúde Coletiva, Rio de Janeiro, v. 13, 2008. Disponível em: http://www.redalyc.org/redalyc/ pdf/630/63009618.pdf. Acesso em: 10 out 2018.

MOORE, M. G.; KEARSLEY, G. Educação a Distância: uma visão integrada. São Paulo: Cengage Learning. 398f. 2008.

MORAN, J. M. Mudando a educação com metodologias ativas. In: SOUZA, C. A. de; MORALES, O. E. T. (Org.). Coleção Mídias Contemporâneas. Convergências Midiáticas, Educação e Cidadania: aproximações jovens. Vol. II. PG: Foca Foto-PROEX/UEPG, 2015.

OROJA, S. G.; KOTOUA, S.; ILKAN, M. Online Education in North Cyprus Universities: Case Study Eastern. Procedia: Social and Behavioral Sciences, Turkey, n. 28, p. 536-541, 2011.

SARDO, Pedro Miguel Garcez. Aprendizagem baseada em problemas em reanimação cardiopulmonar no ambiente virtual de aprendizagem Moodle $^{\circledR}$. 2007. 226p. Dissertação (Mestrado em Enfermagem) - Universidade Federal de Santa Catarina, Florianópolis, 2007. Disponível em: https://repositorio.ufsc.br/ handle/123456789/90664. Acesso em: 10 nov. 2018.
SAVERY, J. R. Overview of problem-based learning: Definitions and distinctions. Interdisciplinary Journal of Problem-based Learning, v. 1, n. 1, p. 3, 2006.

SILVA, C. E. J. da; OLIVEIRA, M. A. S. de. A correlação entre peer instruction e blended learning: um estudo de caso na educação superior. In: CIAED CONGRESSO INTERNACIONAL ABED DE EDUCAÇÃO A DISTÂNCIA, 23., 2017, Foz do Iguaçu - Pr. Anais. Rio de Janeiro RJ: ABED, 2017. p. 1 - 8. Disponível em: http://www.abed.org.br/ congresso2017/trabalhos/pdf/55.pdf. Acesso em: 11 nov. 2018.

SOARES JUNIOR, C. P.; PORTO, M. D. A descoberta de novos ambientes e possibilidades: o fim das fronteiras por meio das metodologias ativas. In: 23 CIAED CONGRESSO INTERNACIONAL ABED DE EDUCAÇÃO A DISTÂNCIA, 2017, Foz do Iguaçu. Anais. Foz do Iguaçu: ABED, 2017. p. 1-10. Disponível em: http://www.abed.org.br/ congresso2017/trabalhos/pdf/419.pdf. Acesso em: 1 out. 2018.

TORI, R. Cursos híbridos ou blended learning. In: LITTO, F.; FORMIGA, M. Educação a distância: o estado da arte. São Paulo: Pearson Education do Brasil, 2009.

VALENTE, J. A. Blended learning e as mudanças no ensino superior: a proposta da sala de aula invertida. Educar em Revista, Curitiba, Brasil, Edição Especial n. 4/2014, p. 79-97. Editora UFPR. DOI: 10.1590/0104-4060.38645.

Data de recebimento: 25/05/2019

Data de aprovação: 26/08/2019 


\section{SOBRE OS AUTORES}

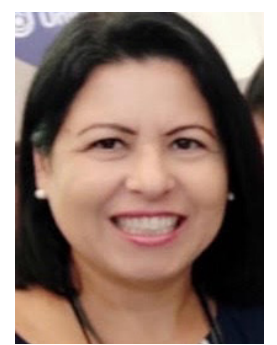

\section{Ana Elisa Pillon}

Doutoranda no Programa de Pós-Graduação em Engenharia e Gestão do Conhecimento(PPGEGC/ UFSC), na área de Mídia do Conhecimento (início em 2019/1). Possui Mestrado Profissionalem Engenharia de Produção pela Unisociesc (2016). Possui graduação em Psicologia (Bacharelado) pela Universidade do Vale do Itajaí (2004) e Especialização em Gestão de Recursos Humanos pela Faculdade Estácio de Sá (2007). Tem experiência na área de Educação, atuando principalmente nos seguintes temas: inovações educacionais, psicologia, gestão de pessoas, ética, relações interpessoais e Educação a Distância. Na Unisociesc leciona (ou já lecionou) presencialmente as disciplinas de Psicologia Jurídica (no curso de Direito), Psicologia aplicada à Administração e Comportamento Organizacional (no curso de Administração - FGV), Plano de Carreira (no curso Tecnologia em Recursos Humanos); Ética e Responsabilidade Social (nos cursos de Bacharelado de Sistemas da Informação, Engenharia da Computação, Tecnologia da Qualidade, Tecnologia em Recursos Humanos, Tecnologia em Processos Gerenciais, Tecnologia em Gestão Financeira, Tecnologia em Logística e Tecnologia em Jogos Digitais), Metodologia científica (no curso de Tecnologia em Jogos Digitais), LAI Laboratório de Aprendizagem Integrada (em cursos variados) e Fundamentos de Gestão de Pessoas (no curso de Ciências Contábeis). Além disso atua nas disciplinas de Gestão de Pessoas, Treinamento e desenvolvimento, Relações Interpessoais, Recrutamento e Seleção de Talentos, Ética e Responsabilidade Social, Psicologia da
Aprendizagem e Psicologia Organizacional na modalidade de Educação a Distância (professora tutora da Educação a Distância da Ânima Digital desde 2013). Os temas de interesse de pesquisa são: ensino-aprendizagem na $\mathrm{EaD}$, gestão de cursos EaD, Tecnologia Educacional, Sustentabilidade, Empreendedorismo, Liderança, Mídia do Conhecimento, Gestão do Conhecimento e Educação em Rede. Atua no Grupo de Pesquisa Mídia e Conhecimento/GPMC - PPGEGC/ UFSC - sob Coordenação do Prof. Dr. Márcio Vieira de Souza.

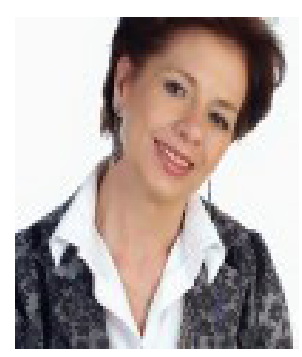

\section{Araci Hack Catapan}

Possui graduação em Pedagogia pela Faculdade de Filosofia Ciências e Letras de Palmas (1982), mestrado em Educação pela Universidade Federal de Santa Catarina (1993) e doutorado em Engenharia de Produção pela Universidade Federal de Santa Catarina (2001). Especialista em Curriuclo e Filosofia pela PUCMG. Atualmente é professora associada II da Universidade Federal de Santa Catarina. Tem experiência em todos os níveis de Educação. Atua em pesquisa, ensino e extensão, com ênfase nos seguintes temas: Educação a Distância (EaD), cibercultura,tecnologia, Gestão de conheicmento, midia e conheciento, pedagogia digital, formação de professores, tecnologia de comunicação digital e software. Atua nos programas de Pós Graduação da Engenharia e Gestão do Conhecimento e no Programa de pós-graduação em Educação.É consultora para os sistemas UAB/ CAPES e Rede e_Tec Brasil. É coordenadora do núcleo de pesquisa Científica em Educação 
a Distância CNPq. É participante do Grupo de Pesquisa em Avaliação e Gestão na Educação (CNPq ? DGP). Coordena o núcleo de ensino pesquisa e extensão ATELIERTCD/CED/UFSC e os Projetos de pesquisa Currículo Referência para o Sistema e-Tec Brasil; metodologias e experiências exitosas na implementação da Rede e-Tec: Objetos Digitais de Ensino-aprendizagem. Participa como Pesquisadora no projeto de certificação de tecnologias educacionais/SEB/ MEC. Faz parte do conselho editorial da revista TRAVESSIAS. Pertence ao comitê científico da ABED. Coordenadora da Comissão Própria de Avaliação Institucional da UFSC de 2004 a 2008. Diretora de Ensino de graduação 2004 a 2006 e diretora de Educação a Distância 2005 a 2008, na UFSC. Líder do Laboratório de Habitats de Inovação e Empreendedorismo www.inlab.ufsc.br.

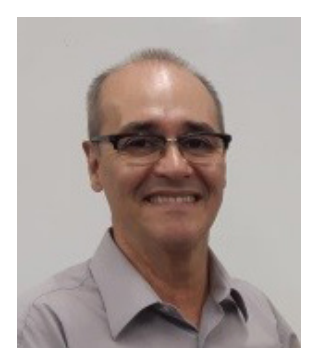

\section{Márcio Vieira de Souza}

Possui graduação em Comunicação Social (Habilitação- Jornalismo) pelaUniversidade do Vale do Rio dos Sinos (1985), especialização em Educação (duas) (UFSC,UNIVALI). Mestrado em Sociologia Política pela Universidade Federal de Santa Catarina (1995) e Doutorado em Engenharia de Produção pela Universidade Federalde Santa Catarina (2002). Tem experiência na área de mídia e conhecimento, comunicação, sociologia política, Educação a Distância, mídias digitais, atuando principalmente nos seguintes temas: comunicação e educação, mídia e conhecimento, inovação na educação, educação em rede, sociologia e tecnologia, redes e mídias sociais, Análise de redes sociais (ARS), vídeo e democracia, desenvolvimento sustentável e tecnologias da informação e da comunicação (TIC), metodologia de pesquisa e metodologias ativas na educação. Foi chefe de departamento do curso de jornalismo da UNIVALI-SC, foi professor no Mestrado do Programa de Pós-graduação em Gestão em Políticas Públicas da UNIVALI-SC. Foi professor permanente do PPGTIC-UFSC. É professor Associado da Universidade Federal de Santa Catarina (UFSC) onde é um dos lideres do Grupo de Pesquisa de Mídia e Conhecimento da UFSC (CNPq) e atua no Departamento de Engenharia e Gestão do Conhecimento (DEGC-UFSC). Foi Supervisor do LED-UFSC ( Laboratório de Educação a Distância).

É professor permanente no Programa de Pós-graduação em Engenharia e Gestão do Conhecimento (PPGEGC-UFSC). É Coordenador do LabMídia (laboratório de Mídia e conhecimento) da UFSC.

\section{***}

